\title{
Ionic-Liquid-Mediated MacMillan's Catalyst for Diels-Alder Reaction
}

\author{
Vivek Srivastava \\ Applied Science, NIIT University, Neemrana, Alwar, Rajasthan 301705, India \\ Correspondence should be addressed to Vivek Srivastava; vivek.srivastava.chem@gmail.com
}

Received 4 June 2012; Accepted 14 November 2012

Academic Editor: Antonia Pérez de los Ríos

Copyright ( 2013 Vivek Srivastava. This is an open access article distributed under the Creative Commons Attribution License, which permits unrestricted use, distribution, and reproduction in any medium, provided the original work is properly cited.

Ionic liquids were used to enhance as well as recycle the MacMillan's catalyst $\mathbf{1}$ for the Diels-Alder reaction. Using our developed protocol, Diels-Alder adducts were obtained in good yields and selectivities along the 6 times recycling of MacMillan's imidazolidinone catalyst $\mathbf{1}$. Synthesis of steroid 4 is the major outcome of our developed protocol.

\section{Introduction}

Over the past decade, the Diels-Alder reaction is found highly applicable as the most powerful organic reaction in area of chemical synthesis [1-5]. In recent times much interest has been developed for the synthesis of highly efficient organocatalysts for a variety of organic transformations [6-10]. MacMillan and coworkers have initially reported (5S)-2,2,3-trimethyl-5-phenylmethyl-4-imidazolidinone monohydrochloride catalyst (MacMillan's imidazolidinone catalyst $\mathbf{1}$ ), as a promising organocatalyst for the Diels-Alder reaction via a LUMO-lowering activation reaction mechanism $[8,11,12]$. Although the MacMillan's imidazolidinone catalyst $\mathbf{1}$ was found highly active in terms of yield and selectivity but still this catalyst has suffered from various drawbacks like the need for high catalyst loading, requirement of polar solvents, catalyst recycling, and so forth [13-17]. To avoid such drawbacks and to make the MacMillan's imidazolidinone catalyst $\mathbf{1}$ more convenient for DielsAlder reaction, various approaches have been reported from different groups to support this MacMillan's imidazolidinone catalyst 1 via ionic liquids [13], polymethylhydrosiloxane polymer [14], Montmorillonite [15], and so forth. The supported organocatalysts seem particularly attractive because they offer homogeneous/heterogeneous reactions medium, high selectivity, low catalyst loading, catalyst recycling, and so forth, but this supported system also carries various demerits like requirement of costly starting materials, long preparation steps (3-4 steps), tedious work-up procedures, and lack of catalyst recycling.

In various reports, ionic liquids were also identified as an alternative solvent to immobilize not only to MacMillan's imidazolidinone catalyst $\mathbf{1}$ for the Diels Alder reaction [16, 17] but some organocatalysts too for various useful organic transformations. Recycling of catalytic, low catalyst loading and option to avoid the use of polar solvents are the major outcomes of ionic-liquid-mediated catalysis [17]. Considering the above facts and merits of ionic liquid immobilized organocatalysis, we initiated our work in the area of ionic liquid immobilized MacMillan's imidazolidinone catalyst $\mathbf{1}$ for Diels-Alder reaction.

\section{Experimental Procedure}

All the chemicals were purchased from Sigma Aldrich, Acros, or SD fine chemicals, and all the experiments were carried out under nitrogen unless noted. NMR spectra were recorded on standard Bruker300WB spectrometer with an Avance console at 300 and $75 \mathrm{MHz}$ for ${ }^{1} \mathrm{H}$ and ${ }^{13} \mathrm{C}$ NMR, respectively. Enantiomeric excesses were determined by chiralphase HPLC: Waters 600E System Controller and Waters 996 Photodiode Array Detector Column with Chiralcel AS-H, Chiralcel OD-H, and Chiralcel AD-H column from Daicel 
TABLE 1: Screening of different ionic liquids for MacMillan's imidazolidinone catalyst $\mathbf{1}$ catalysed Diels-Alder reaction between cyclohexene 1 and acrolein 2 .

\begin{tabular}{|c|c|c|c|c|c|}
\hline Entry & Ionic liquid & Ionic liquid amount (in mmol) & Yield $^{\mathrm{a}}(\%)$ & endo:exo ${ }^{\mathrm{b}}$ & ee $(\%)^{\mathrm{c}}$ \\
\hline \multirow{2}{*}{ (1) } & \multirow{2}{*}[\mathrm{bmim}]{$[\mathrm{Cl}]$} & 0.05 & 64 & $1.5: 1$ & 65 \\
\hline & & 0.10 & 63 & $1.6: 1$ & 67 \\
\hline \multirow{2}{*}{$(2)$} & \multirow{2}{*}[\mathrm{bmim}]{$\left[\mathrm{PF}_{6}\right]$} & 0.05 & 68 & $1.8: 1$ & 71 \\
\hline & & 0.10 & 70 & $2.2: 1$ & 74 \\
\hline \multirow{6}{*}{ (3) } & \multirow{6}{*}[\mathrm{bmim}]{$\left[\mathrm{NTf}_{2}\right]$} & 0.01 & 65 & $3: 1$ & 71 \\
\hline & & 0.02 & 68 & $3.5: 1$ & 78 \\
\hline & & 0.05 & 84 & $4.2: 1$ & 88 \\
\hline & & 0.10 & 91 & $5.6: 1$ & 92 \\
\hline & & 0.5 & 94 & $19: 1$ & 95 \\
\hline & & 1 & 92 & $96: 1$ & 91 \\
\hline$(4)$ & $\mathrm{MeOH} / \mathrm{H}_{2} \mathrm{O}$ & $0.95 \mathrm{~mL}: 0.05 \mathrm{~mL}$ & 8 & $2.3: 1$ & 87 \\
\hline$(5)$ & $\mathrm{CH}_{3} \mathrm{CN} / \mathrm{H}_{2} \mathrm{O}$ & $0.95 \mathrm{~mL}: 0.05 \mathrm{~mL}$ & 84 & $2.3: 1$ & 90 \\
\hline
\end{tabular}

${ }^{\mathrm{a}}$ Isolated yield, ${ }^{\mathrm{b}}$ endo : exo ratio was determined by ${ }^{1} \mathrm{H}$ NMR, ${ }^{\mathrm{c}}$ ee\% was determined by HPLC, ${ }^{\mathrm{d}} 1 \mathrm{~mL} \mathrm{MeOH} / \mathrm{H}_{2} \mathrm{O}$ system.

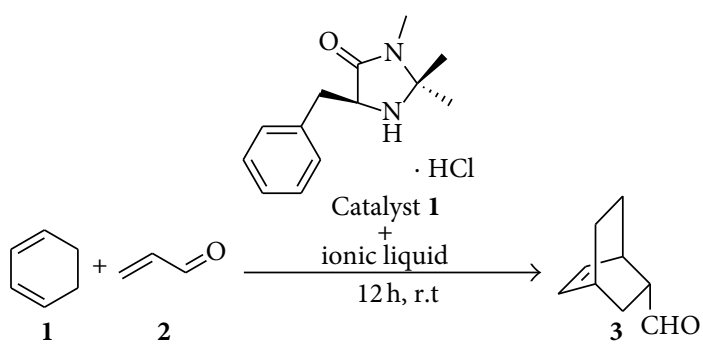

Scheme 1: Ionic-liquid-mediated Diels-Alder reaction.

Chemical Industries Ltd., eluting with $n$-hexane and 2propanol.

\subsection{General Methods for Ionic Liquid Mediated Diels-Alder} Reaction. Ionic liquid $(0.5 \mathrm{mmoL})$ or $\mathrm{MeOH}(0.95 \mathrm{~mL}) /$ Water $(0.05 \mathrm{~mL})$ or $\mathrm{CH}_{3} \mathrm{CN}(0.95 \mathrm{~mL}) /$ water $(0.05 \mathrm{~mL})$, MacMillan's imidazolidinone catalyst $1(0.02 \mathrm{mmol})$, cyclohexadiene $1(0.5 \mathrm{mmol})$, acroline $2(2.5 \mathrm{mmol})$, and $\mathrm{CF}_{3} \mathrm{COOH}$ ( $5 \mathrm{moL} \%)$ were allowed to stir for $12 \mathrm{~h}$ at room temperature. The corresponding reaction product from the well-dried reaction mass (dried under high vacuum at $50^{\circ} \mathrm{C}$ for 1 hour in order to remove all volatile impurities) was extracted with ether $(5 \times 2 \mathrm{~mL})$. Combined organic layers were dried over high vacuum, and the reaction mixture was further purified by column chromatography.

2.2. Recycling of the Catalytic System. The recycling experiments were carried out using $[\mathrm{bmim}]\left[\mathrm{NTf}_{2}\right](0.5 \mathrm{mmol})$ and MacMillan's imidazolidinone catalyst $1(0.02 \mathrm{mmol})$ for the model Diels-Alder reaction between cyclohexadiene $\mathbf{1}$ (0.5 mmol), acroline 2 (2.5 mmol), and $\mathrm{CF}_{3} \mathrm{COOH}(5 \mathrm{moL} \%)$ at RT for $12 \mathrm{~h}$. After completion of the first run, the reaction product was isolated with simple ether washing. The remaining reaction mass was allowed to dry under high vacuum at $50^{\circ} \mathrm{C}$ for 1 hour in order to remove all the volatile impurities from the reaction mass and then the reaction mass (mixture of [bmim] $\left[\mathrm{NTf}_{2}\right] /(5 S)$-2,2,3-trimethyl-5-phenylmethyl4-imidazolidinone monohydrochloride) subjected to DielsAlder reaction.

2.3. Synthesis of Steroid 4. Ionic liquid ( $0.5 \mathrm{mmol})$, MacMillan's imidazolidinone catalyst $1(0.02 \mathrm{mmol}), 7$-methoxy4-vinyl-1,2-dihydronaphthalene $\mathbf{1}(0.5 \mathrm{mmol}), 2$-Bromo-propenal $2(2.5 \mathrm{mmol})$, and $\mathrm{CF}_{3} \mathrm{COOH}(5 \mathrm{moL} \%)$ were allowed to stir for $12 \mathrm{~h}$ at room temperature. The corresponding reaction product from the well-dried reaction mass (dried under high vacuum at $50^{\circ} \mathrm{C}$ for 1 hour in order to remove all the volatile impurities) was extracted with hexane:ethylacetate (20\% mixture) $(5 \times 2 \mathrm{~mL})$. Combined organic layers were dried over high vacuum, and the reaction mixture was further purified by column chromatography.

\section{Result and Discussion}

As reported in Table 1, three different types of ionic liquid like $[\mathrm{bmim}][\mathrm{Cl}],[\mathrm{bmim}]\left[\mathrm{PF}_{6}\right]$, and $[\mathrm{bmim}]\left[\mathrm{NTf}_{2}\right]$ were tested as a reaction medium for MacMillan's imidazolidinone catalyst 1 to catalyzed our model Diels-Alder reaction between cyclohexadiene $\mathbf{1}$ and acrolein $\mathbf{2}$ (Scheme 1 and Table 1, Entry 1-3). As shown in Table 1 at room temperature our 
TABLE 2: Screening of Acid cocatalysts for $[\mathrm{bmim}]\left[\mathrm{NTf}_{2}\right]$ mediated Diels-Alder reaction with MacMillan's imidazolidinone catalyst $\mathbf{1}$.

\begin{tabular}{|c|c|c|c|c|}
\hline Entry & Acid co-catalyst & Yield $^{\mathrm{a}}(\%)$ & endo:exo ${ }^{\mathrm{b}}$ & $\mathrm{ee}^{\mathrm{c}}(\%)$ \\
\hline (1) & $\mathrm{CF}_{3} \mathrm{COOH}$ & 98 & $19: 1$ & 97 \\
\hline (2) & $\mathrm{CH}_{3} \mathrm{COOH}$ & 90 & $19: 1$ & 95 \\
\hline (3) & $\mathrm{TfOH}$ & 95 & $18: 1$ & 94 \\
\hline (4) & $p$-TSA & 96 & $18: 1$ & 92 \\
\hline (5) & $\mathrm{Cl}_{3} \mathrm{COOH}$ & 20 & $17: 1$ & 87 \\
\hline (6) & $\mathrm{HCl}$ & 75 & $17: 1$ & 92 \\
\hline (7) & $\mathrm{Ph}-\mathrm{COOH}$ & 76 & $17: 1$ & 89 \\
\hline
\end{tabular}

${ }^{\mathrm{a}}$ Isolated yield, ${ }^{\mathrm{b}}$ endo : exo ratio was determined by ${ }^{1} \mathrm{HNMR},{ }^{\mathrm{c}} \mathrm{ee} \%$ was determined by HPLC.

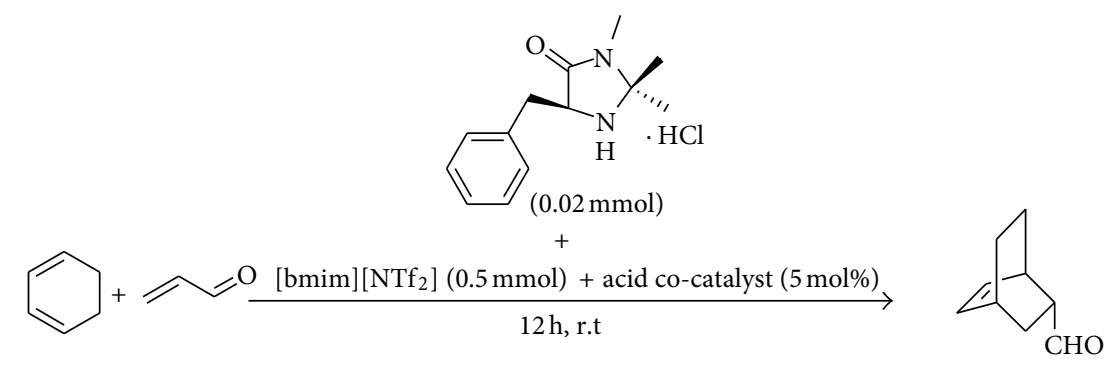

Scheme 2: $[$ bmim $]\left[\mathrm{NTf}_{2}\right]$ mediated Diels-Alder reaction with MacMillan's imidazolidinone catalyst $\mathbf{1}$.

model Diels-Alder reaction enjoyed a lot with [bmim] $\left[\mathrm{NTf}_{2}\right]$ $(0.5 \mathrm{mmol})$ mediated catalyst $\mathbf{1}$ and offered the desired product 3 with high yield (82\% yield) and selectivity (24: 1 endo:exo, 94\% ee). Comparatively, lower yields and selectivities were obtained for the same model reaction (Table 1, Entry 1,2$)$ with both $[\mathrm{bmim}][\mathrm{Cl}]$ and $\left[\mathrm{bmim}^{\mathrm{b}}\right]\left[\mathrm{PF}_{6}\right]$, as the MacMillan's imidazolidinone catalyst $\mathbf{1}$ was almost insoluble in both $[\mathrm{bmim}][\mathrm{Cl}]$ and $[\mathrm{bmim}]\left[\mathrm{PF}_{6}\right]$. Instead of ionic liquids, MacMillan's imidazolidinone catalyst $\mathbf{1}$ was also treated with $\mathrm{MeOH} / \mathrm{H}_{2} \mathrm{O}$ solvent system for same model Diels-Alder reaction. The corresponding product 3 was obtained in an acceptable yield (68\%) along with $2.3: 1$ endo: exo ratio and $72 \%$ ee.

Various acids were also tested to improve the yield and selectivity of Diels-Alder reaction (Table 2 and Scheme 2). The utilization of $\mathrm{CF}_{3} \mathrm{COOH}$, TfOH, $\mathrm{CH}_{3} \mathrm{COOH}$ and $p$-TSA led to relatively good yields and selectivity for [bmim] $\left[\mathrm{NTf}_{2}\right]$ mediated Diels-Alder reaction with MacMillan's imidazolidinone catalyst 1 . In contrast, relatively high yield (98\%) and excellent enantioselectivity (97\%) with good endo: exo ratio were obtained ( $>19: 1$ ) and produced when $\mathrm{CF}_{3} \mathrm{COOH}$, was selected. Thus, $\mathrm{CF}_{3} \mathrm{COOH}$ was identified as the optimal acidic cocatalyst.

Having the optimized reaction condition for Diels-Alder reaction by utilizing MacMillan's imidazolidinone catalyst $\mathbf{1}$ and $[\mathrm{bmim}]\left[\mathrm{NTf}_{2}\right]$ as the reaction solvent, we subsequently applied the optimized reaction condition to various substrates to explore the generality of the reaction system. As summarized in Table 3, entry 1-10, The Diels-Alder reaction involving various $\alpha, \beta$-unsaturated aldehydes and different cyclic dienes proceeded efficiently in the presence of MacMillan's imidazolidinone catalyst $\mathbf{1}$ in [bmim] $\left[\mathrm{NTf}_{2}\right]$, loading the corresponding products in good yield with excellent enantioselectivities. The comparable ee's were obtained in contrast to the use of imidazolidinone as a reaction catalyst which was previously reported by MacMillan and coworkers. For example, when trans-cinnamaldehyde was used as substrate, the utilization of MacMillans's imidazolidinone catalyst 1 affords the desired product in 93\% ee. Likewise, by employing [bmim] $\left[\mathrm{NTf}_{2}\right]$ reaction solvent for MacMillan's imidazolidinone catalyst $\mathbf{1}$ in the Diels-Alder reaction almost similar results were achieved as well (Table 3, entry 10) [11].

With the success of the above reactions, we embark to test our modified protocol for the synthesis of steroids via Diels-Alder reaction, using complex open-chain diene and 7-methoxy-4-vinyl-1,2-dihydronaphthalene (Scheme 3) [18]. The cycloadduct 4 was obtained with a good enantiomeric excess $(80 \%)$ and chemical yield (70\%).

Next, we continued our study by exploring the recycling of MacMillan's imidazolidinone catalyst $\mathbf{1}$ for our model Diels-Alder reaction using $[\mathrm{bmim}]\left[\mathrm{NTf}_{2}\right]$ as solvent (Scheme 4); after completion, the reaction product was extracted with ether. The MacMillan's imidazolidinone catalyst $\mathbf{1} /[\mathrm{bmim}]\left[\mathrm{NTf}_{2}\right]$ residue was dried under high vacuum at $50^{\circ} \mathrm{C}$ for 1 hour to facilitate the removal of volatile remnants prior to subsequent addition of the cyclohexadiene and acroline in the next cycle (Scheme 4). The results are shown in Table 4.

It was noteworthy that the MacMillan's imidazolidinone catalyst 1 can be recycled for seven successive runs with comparable enantioselectivities and yields without loss of catalytic activity. Moreover, the extraction process was operationally simple, which offers easy product separation. 
TABLE 3: [bmim] $\left[\mathrm{NTf}_{2}\right]$ mediated MacMillan's imidazolidinone catalyst $\mathbf{1}$ catalysed, Diels-Alder reaction of various dienes with dienophiles.

\begin{tabular}{|c|c|c|c|c|c|}
\hline Entry & Diene & Dienophiles & Yield $^{\mathrm{a}}(\%)$ & endo:exo ${ }^{\mathrm{b}}$ & ee $(\%)^{c}$ \\
\hline (1) & & & 98 & $19: 1$ & 97 \\
\hline (2) & & & 90 & $1.5: 1$ & 92 \\
\hline (3) & & & 97 & $3: 1$ & 96 \\
\hline (4) & & & 85 & $1.5: 1$ & 97 \\
\hline (5) & & & 95 & $49: 1$ & 98 \\
\hline (6) & & & 98 & $99: 1$ & 95 \\
\hline (7) & & & 99 & $1.1: 1$ & 78 \\
\hline (8) & & & 88 & $1.1: 1$ & 88 \\
\hline (9) & & & 90 & $1: 1$ & 89 \\
\hline (10) & & & 99 & $1.2: 1$ & 92 \\
\hline
\end{tabular}

${ }^{\mathrm{a}}$ Isolated yield, ${ }^{\mathrm{b}}$ endo : exo ratio was determined by ${ }^{1} \mathrm{H}$ NMR crude reaction product, ${ }^{\mathrm{c}}$ ee $\%$ or was determined by HPLC or GC analysis.

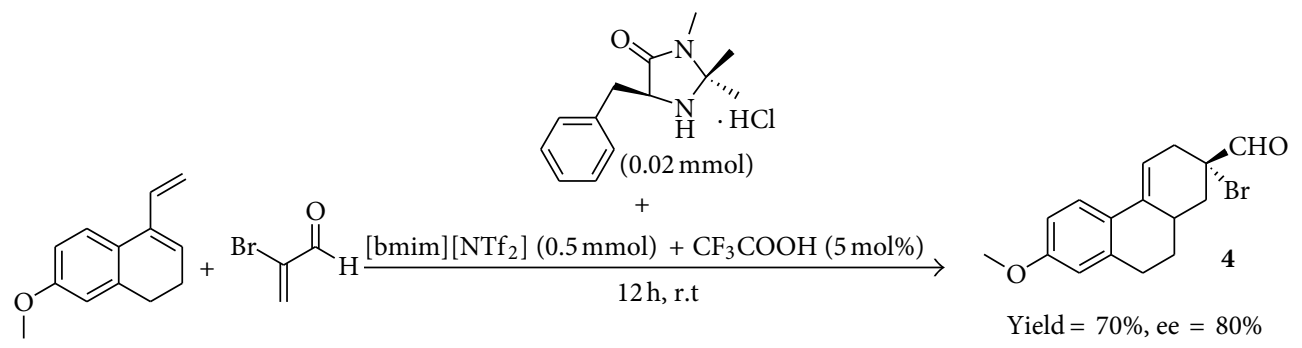

Scheme 3: Synthesis of steroids using the developed methodology.

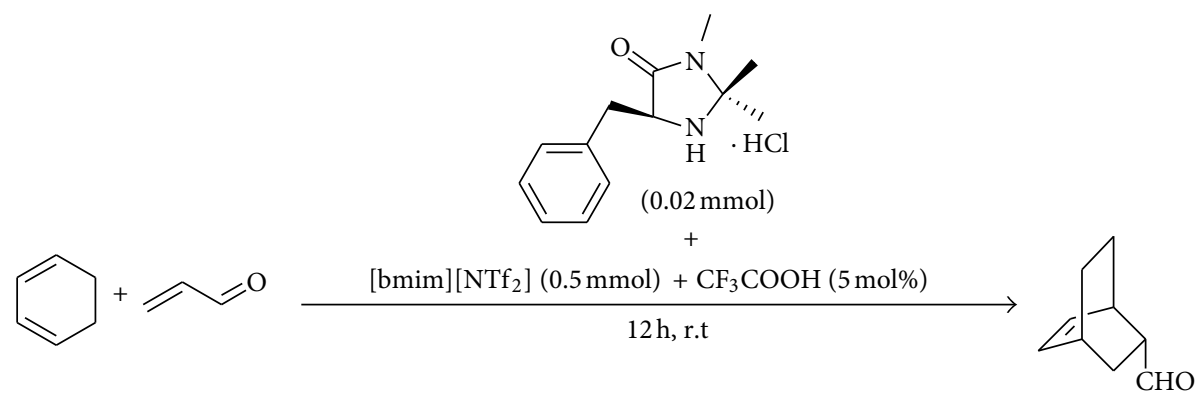

SCHEME 4: Recycling experiment for MacMillan's imidazolidinone catalyst $\mathbf{1}$. 
TABLE 4: Recyclability of MacMillan's imidazolidinone catalyst $\mathbf{1} /[$ bmim $]\left[\mathrm{NTf}_{2}\right]$ system.

\begin{tabular}{lccc}
\hline No. of cycles & ${\text { Yield }(\%)^{\mathrm{a}}}$ & ${\text { endo }: \text { exo }^{\mathrm{b}}}$ & ee $(\%)^{\mathrm{c}}$ \\
\hline$(1)$ & 98 & $19: 1$ & 97 \\
$(2)$ & 97 & $19: 1$ & 97 \\
$(3)$ & 94 & $19: 1$ & 97 \\
$(4)$ & 92 & $19: 1$ & 96 \\
$(5)$ & 90 & $17: 1$ & 97 \\
$(6)$ & 92 & $17: 1$ & 95 \\
\hline
\end{tabular}

${ }^{\mathrm{a}}$ Isolated yield, ${ }^{\mathrm{b}}$ endo : exo ratio was determined by ${ }^{1} \mathrm{HNMR}$ crude reaction product, ${ }^{c} \mathrm{ee} \%$ or was determined by HPLC.

\section{Conclusion}

In conclusion, we developed a modified and improved protocol for MacMillan's imidazolidinone catalyst 1 DielsAlder reaction using ionic liquid as the reaction media and we successfully obtained enantiomerically enriched DielsAlder adducts with high yields and selectivities. The main features of this reaction are as follows: (1) the procedure is operationally simple; (2) the cycloaddition adducts were obtained in good yield and selectivities for variety various dienes with dienophiles resulted in good yields and high selectivity. (3) We obtained the cyclyoddition adduct with low catalyst loading $(0.02 \mathrm{mmol}$ instead of $0.036 \mathrm{mmol})$; (4) the catalyst can be recycled up to six cycles with comparable yields and selectivities. (5) Our modified protocol was found active in the synthesis of a tedious steroid 4 molecule.

\section{References}

[1] O. Diels and K. Alder, "Synthesen in der hydroaromatischen Reihe," Justus Liebigs Annalen Der Chemie, vol. 460, pp. 98-122, 1928.

[2] K. C. Nicolaou, S. A. Snyder, T. Montagnon, and G. Vassilikogiannakis, "The diels-alder Rreaction in total synthesis," Angewandte Chemie International Edition, vol. 41, pp. 1668-1698, 2002.

[3] T. J. Brocksom, J. Nakamura, M. L. Ferreira, and U. Brocksom, "The Diels-Alder Reaction: an Update," Journal of the Brazilian Chemical Society, vol. 12, no. 5, pp. 597-622, 2001.

[4] B. S. Bodnar and M. J. Miller, "The nitrosocarbonyl HeteroDiels-Alder reaction as a useful tool for organic syntheses," Angewandte Chemie International Edition, vol. 50, pp. 5630-5647, 2011.

[5] E. M. Stocking and R. M. Williams, "Chemistry and biology of biosynthetic Diels-Alder reactions ", Angewandte Chemie International Edition, vol. 42, pp. 3078-3115, 2003.

[6] M. J. Gaunt, C. C. C. Johansson, A. McNally, and N. T. Vo, "Enantioselective organocatalysis," Drug Discovery Today, vol. 12, no. 1-2, pp. 8-27, 2007.

[7] R. C. Wende and P. R. Schreiner, "Evolution of asymmetric organocatalysis: multi- and retrocatalysis," Green Chemistry, vol. 14, pp. 1821-1849, 2012.

[8] D. W. C. MacMillan, "The advent and development of organocatalysis,” Nature, vol. 455, no. 7211, pp. 304-308, 2008.
[9] S. Bertelsen and K. A. Jorgensen, "Organocatalysis-after the gold rush ," Chemical Society Reviews, vol. 38, pp. 2178-2189, 2009.

[10] J. Seayad and B. List, "Asymmetric organocatalysis," Organic and Biomolecular Chemistry, vol. 3, pp. 719-724, 2005.

[11] K. A. Ahrendt, C. J. Borths, and D. W. C. MacMillan, "New strategies for organic catalysis: the first highly enantioselective organocatalytic Diels-Alder reaction," Journal of the American Chemical Society, vol. 122, no. 17, pp. 4243-4244, 2000.

[12] A. B. Northrup and D. W. C. MacMillan, "The first general enantioselective catalytic Diels-Alder reaction with simple $\alpha, \beta$ unsaturated ketones," Journal of the American Chemical Society, vol. 124, no. 11, pp. 2458-2460, 2002.

[13] Z. L. Shen, H. L. Cheong, Y. C. Lai, W. Y. Loo, and T. P. Loh, "Application of recyclable ionic liquid-supported imidazolidinone catalyst in enantioselective Diels-Alder reactions," Green Chemistry, vol. 14, pp. 2626-2630, 2012.

[14] S. Guizzetti, M. Benaglia, and J. S. Siegel, "Poly(methylhydrosiloxane)-supported chiral imidazolinones: new versatile, highly efficient and recyclable organocatalysts for stereoselective DielsAlder cycloaddition reactions," Chemical Communications, vol. 48, pp. 3188-3190, 2012.

[15] T. Mitsudomea, K. Nosea, T. Mizugakia, K. Jitsukawaa, and K. Kaneda, "Reusable montmorillonite-entrapped organocatalyst for asymmetric Diels-Alder reaction," Tetrahedron Letters, vol. 49, pp. 5464-5466, 2008.

[16] J. K. Park, P. Sreekanth, and B. M. Kim, "Recycling chiral imidazolidin-4-one catalyst for asymmetric Diels-Alder reactions: screening of various ionic liquids," Advanced Synthesis and Catalysis, vol. 346, no. 1, pp. 49-52, 2004.

[17] P. D. Maria, "Inside cover:catalytic asymmetric boration of acyclic, $\beta$-unsaturated esters and nitriles (Angew. Chem. Int. Ed. 1/2008)," Angewandte Chemie International Edition, vol. 47, p. 2, 2008.

[18] F. Fu, F. C. Teo, and T. P. Loh, "Catalytic enantioselective DielsAlder reaction in ionic liquid via a recyclable chiral in(III) complex ," Organic Letters, vol. 26, pp. 5999-6001, 2006. 

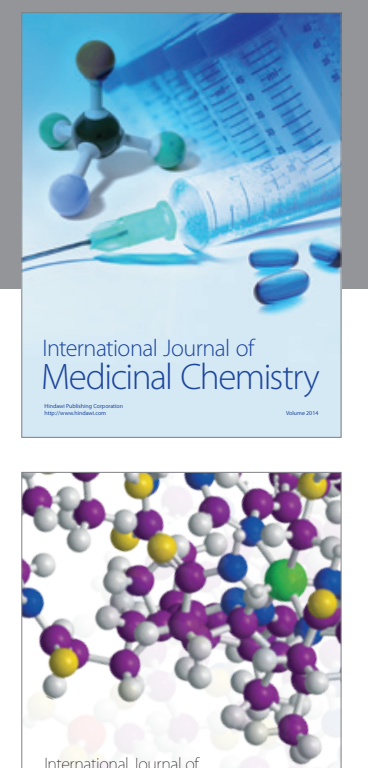

\section{Carbohydrate} Chemistry

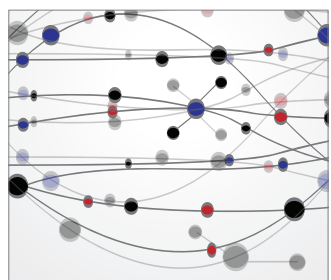

The Scientific World Journal
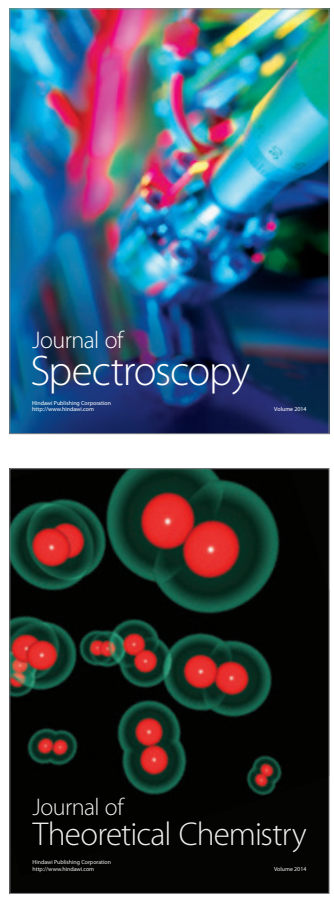
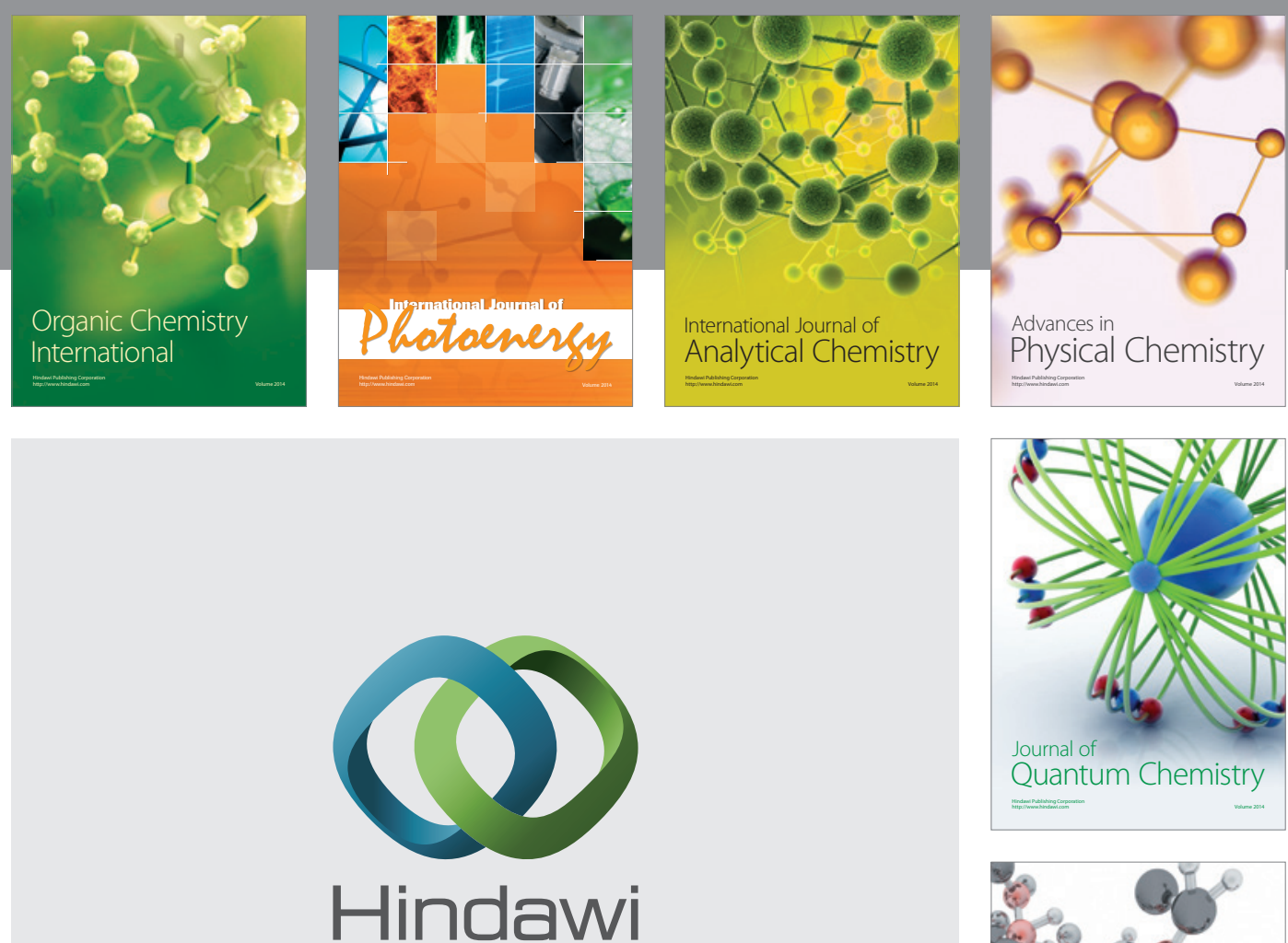

Submit your manuscripts at

http://www.hindawi.com

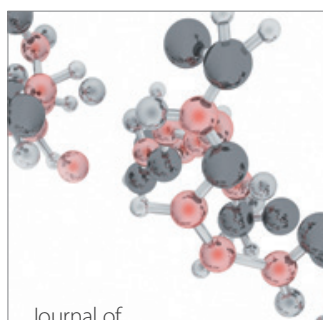

Analytical Methods

in Chemistry

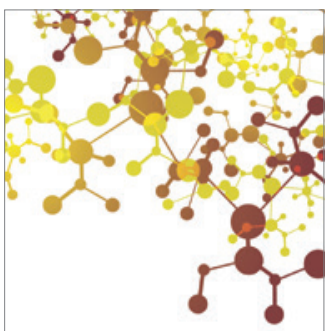

Journal of

Applied Chemistry

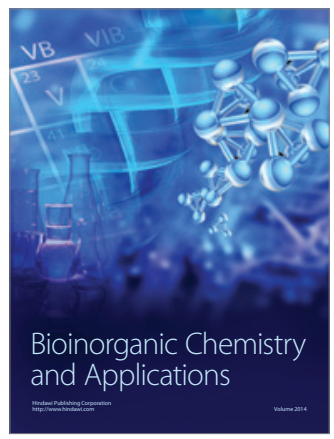

Inorganic Chemistry
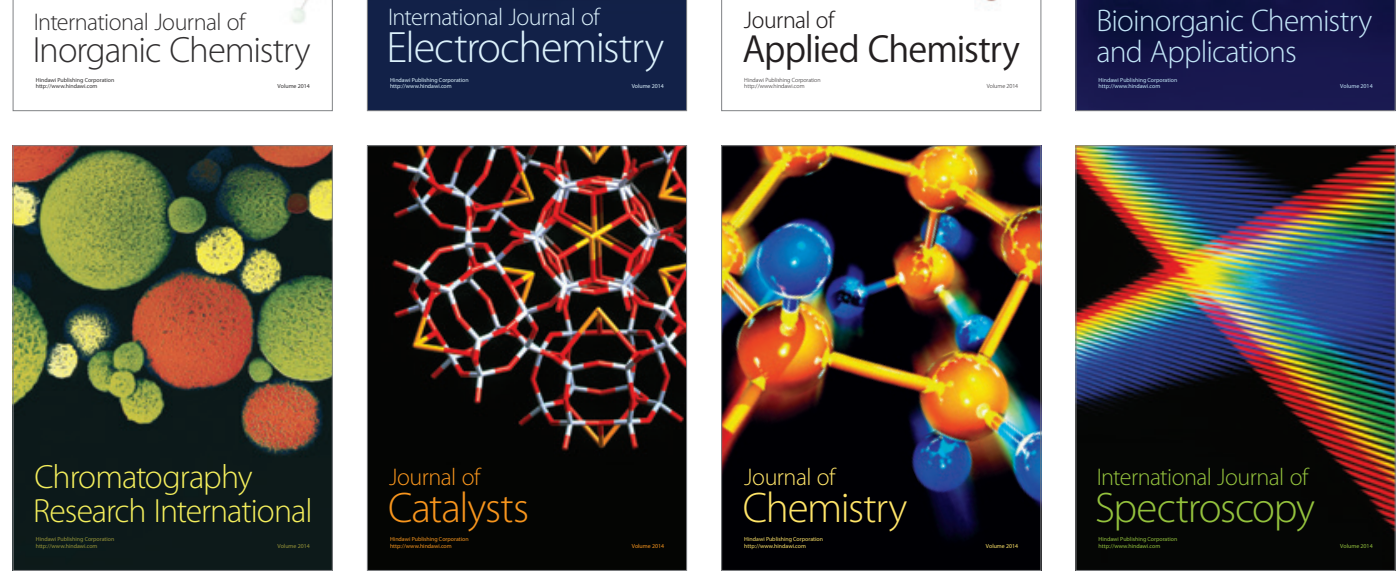